\title{
Xeroradiography: Stagnated after a Promising Beginning? A Historical Review
}

Christopher I. Udoye

Hamid Jafarzadeh ${ }^{b}$

\section{ABSTRACT}

Various methods have been introduced for obtaining radiographs. Xeroradiography which is a method of imaging uses the xeroradiographic copying process to record images produced by diagnostic $x$-rays. It differs from halide film technique in that it involves neither wet chemical processing nor the use of dark room. Literature on this subject is scarce. After an initial promising beginning, this imaging method, once thought to hold the key to endodontic imaging, got stagnated. A revisit of this promising endodontic imaging system would therefore be appropriate. The purpose of this study was to review xeroradiographic technique as a roentgenographic imaging system. (Eur J Dent 2010;4:95-991
\end{abstract}

Key words: Endodontics; Radiography; Xeroradiography.

\section{INTRODUCTION}

For a true diagnosis in endodontics, radiography in conjugation with sensibility tests, vitality tests, and history of the patient can be helpful.1-3

Various methods have been introduced for obtaining radiographs. Xeroradiography which is a method of imaging uses the xeroradiographic

a Faculty of Dentistry, College of Medicine University of Nigeria, Enugu Campus, Nigeria.

b Department of Endodontics, Faculty of Dentistry and Dental Research Center, Mashhad University of Medical Sciences, Mashhad, Iran.

Corresponding author: Dr. Hamid Jafarzadeh Faculty of Dentistry and Dental Research Center Vakilabad Blvd, Mashhad, Iran.

P.O. Box: 91735-984

Phone: +985118829501

Fax: +98 5117626058

E-mail: hamid_j65dyahoo.com JafarzadehBHamums.ac.ir copying process to record images produced by diagnostic $x$-rays. It differs from halide film technique in that it involves neither wet chemical processing nor the use of dark room. ${ }^{4}$

Over the past 40 years, Xerox 125 system became applicable in medical sciences. ${ }^{5}$ A prototype xeroradiographic imaging system specific for intraoral use was later developed. ${ }^{6}$ Following this, clinical trials showed that xeroradiography is superior for imaging of dental structures necessary for successful periodontal and endodontic therapy. ${ }^{7}$ Xeroradiographic radiation of $90 \%$ more than that for silver halide radiograph has been reported, while others found that xeroradiographic radiation is one third to half of that for halide radiograph. ${ }^{8}$

Literature on this subject is scarce. After an initial promising beginning, this imaging method, 
once thought to hold the key to endodontic imaging, got stagnated. A revisit of this promising endodontic imaging system would therefore be appropriate. The purpose of this study was to review xeroradiographic technique as a roentgenographic imaging system.

\section{XERORADIOGRAPHIC DEVELOPMENT}

The imaging method was discovered by an American physicist, Chester Carlson in $1937 .{ }^{9}$ Later, the Xerox Company followed with laboratory investigations of the technique and its potential applications in medical sciences. ${ }^{10}$ Others like Binnie et $a l,{ }^{11}$ Grant et $\mathrm{al}^{12}$ and White et $\mathrm{al}^{13}$ worked on phantoms and cadavers, using the 125 system. Their works led to the development and marketing of intraoral xeroradiographic system.

Xeroradiography may be new in dentistry, but in medicine, it had long been used in the diagnosis of breast diseases, imaging of the larynx, and respiratory tract for foreign bodies, temporomandibular joint, skull, and paraosseous soft tissues. ${ }^{14,15}$

Pogorzelska-Stronczak ${ }^{16}$ became the first to use xeroradiograph to produce dental images, while Xerox 125 medical system got adapted for extraoral dental use in cephalometry, sialography, and panoramic xeroradiography. ${ }^{16,17}$ Later, a prototype xeroradiographic imaging system, specific for intraoral use, was acclaimed to be superior over halide-based intraoral technique. ${ }^{7}$

\section{THE FUNCTIONAL STEPS}

Xeroradiography is an electrostatic process which uses an amorphous selenium photoconductor material, vacuum deposited on an aluminum substrate, to form a plate. The plate, enclosed in light tight cassette, may be likened to films used in halide-based technique. ${ }^{9}$

The key functional steps in the process involve the sensitization of the photoconductor plate in the charging station by depositing a uniform positive charge on its surface with a corona-emitting device called scorotron. ${ }^{18}$ That is, the uniform electrostatic charge placed on a layer of selenium is in electrical contact with a grounded, conductive backing. In the absence of electromagnetic radiation, the photoconductor remains nonconductive and with its uniform electrostatic charge when radiation is passed through an object which will vary the intensity of the radiation, observed Rawls and Owen. ${ }^{19}$ The photoconductor will then conduct its electrostatic charge into the grounded base in proportion to the intensity of the exposure (Figure 1). After charging, the cassette is inserted into a thin polyethylene bag to protect the cassette and plate from saliva. ${ }^{18}$

\section{IMAGE DEVELOPMENT}

The generated latent image is developed through an electrophoretic development process using liquid toner. The process involves the migration to and subsequent deposition of toner particles suspended in a liquid onto an image reception under the influence of electrostatic field forces. ${ }^{18}$ That is, by applying negatively charged powder (toner) which is attracted to the residual positive charge pattern on the photoconductor, the latent image is made visible and the image can be transferred to a transparent plastic sheet or to paper. The toner is thereafter fixed to a receiver sheet onto which a permanent record is made. The plate is then cleaned of toner for reuse. ${ }^{19}$

\section{THE XERORADIOGRAPHIC PLATE}

This plate is made up of a $9 \frac{1}{2}$ by 14 inch sheet of aluminum, a thin layer of vitreous or amorphous selenium photoconductor, an interface layer, and an overcoating on the thin selenium layer (Figure 2). 9,19

\section{THE ALUMINUM SUBSTRATE}

The substrate for the selenium photoconductor should present a clean and smooth surface. Surface defects affect the xeroradiographic plate's sensitivity by giving rise to changes in the electrostatic charge in the photoconductor.?

\section{THE INTERFACE LAYER}

This is a thin layer of aluminum oxide between the selenium photoconductor and aluminum substrate. The oxide is produced by heat treating the aluminum substrate. As a nonconductor, the interface layer prevents charge exchange between the substrate and the photoconductor surface. ${ }^{9}$

\section{THE SELENIUM COATING}

The thickness of this layer varies from $150 \mu \mathrm{m}$ for powder toner development plate to $320 \mu \mathrm{m}$ for liquid toner development. Amorphous or vitreous selenium coating, melting point $216^{\circ} \mathrm{C}$, is formed 
by depositing a vapor form of liquefied selenium in high vacuum. Because of its ease of use, fabrication and durability, inherent property of electrically conducting when exposed to x-rays and ability to insulate well when shielded from all sources of light, make selenium a xeroradiographic material of choice. On the other hand, any form of impurity adversely affects its performance. Amorphous form is used in xeroradiography because crystalline selenium's electrical conductivity is very high which makes it unsuitable in xeroradiography. However, amorphous selenium undergoes a dark decay of about $5 \%$ per minute. A new system of xeroradiography which uses plates with thicker selenium layer $(320 \mu \mathrm{m})$ gives about $50 \%$ x-ray absorption. ${ }^{9}$

\section{SELENIUM PROTECTIVE COATING}

The protective coating is a $0.1 \mu \mathrm{m}$ cellulose acetate overcoat. The coat bonds intimately with selenium photoconductor. It helps to prevent degradation of electrostatic lateral image through the prevention of lateral conduction of electrostatic charges. Also, it impacts positively on the shelf life of the xeroradiographic plate. ${ }^{9}$

\section{POSSIBLE ADVANTAGES OF XERORA- DIOGRAPHY}

Elimination of accidental film exposure

Accidental film exposure is impossible. The reasons being that large light intensity is required for photoconduction and even when there is expo-

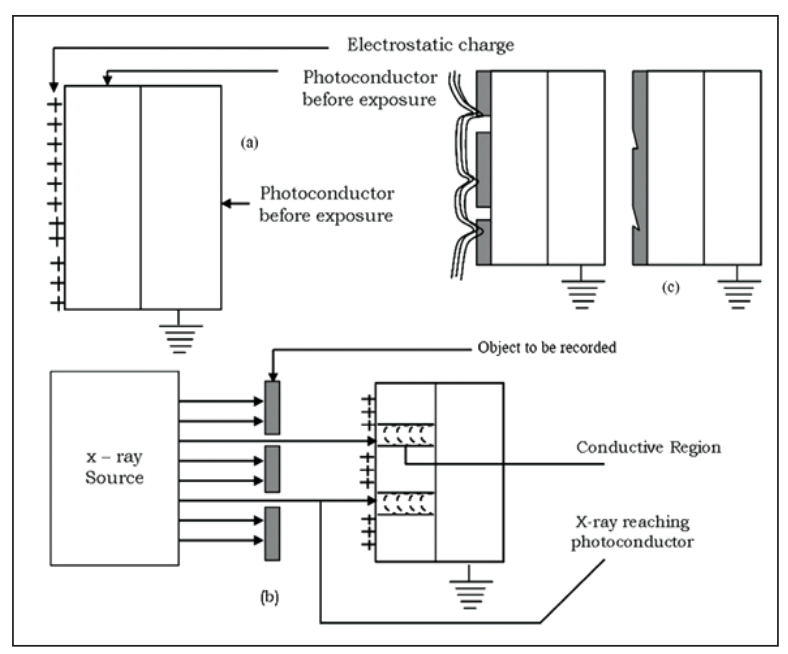

Figure 1. A schematic figure of the xeroradiographic process by Rawls and Owen ${ }^{19}$ : (a) The charged photoconductor acting as an insulator; (b) Exposure ensures charge to be conducted away from the surface; (c) particles collect in charged areas, giving positive image. sure, the charged area intrinsically gets erased. As a result, there is minimal need for storage for film protection during processing. ${ }^{20}$

\section{High resolution}

Xeroradiography has excellent characteristics of the forces around the electrostatic charges which form the latent image. The strengths of the fields are smaller at the centre of charged ones than at the edge, resulting in a greater number of powder particles collections peripherally than in central charged areas. This greatly enhances local contrast which, in turn, improves resolution and image quality. ${ }^{21-23}$

Simultaneous evaluation of multiple tissues

Xeroradiography makes it possible for different tissues to be evaluated in one film, because the technique records tissues of differing thicknesses and densities in a xeroradiograph. ${ }^{21}$

\section{Ease of reviewing}

Use of reflected or transmitted light is allowed by xeroradiography. This is because the image can be mounted either in a transparent plastic sheet or on opaque paper. ${ }^{22}$

\section{Higher latitude of exposure factors}

Little image quality change in xeroradiography will require large kilo-voltage variations. The end point is that chances of incorrect exposure and retakes are highly slim. ${ }^{21}$

\section{Better ease and speed of production}

So far as no special skills are required for office copying machine, even more so is the xeroradiographic process. Furthermore, dark room requirements are unnecessary, and the entire xeroradiographic process may be completed within 60 seconds. The process also allows multiple copies simultaneously. ${ }^{20,21}$

Economic benefit

When compared with halide radiography, an

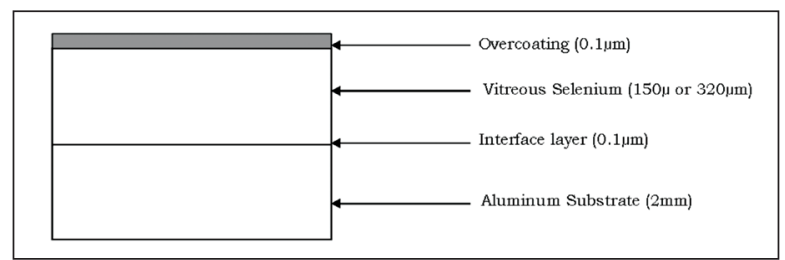

Figure 2. A schematic figure of a xeroradiographic plate. ${ }^{19}$ 
eight fold increase in cost is saved over conventional radiography. This may be due to the peculiar attributes of xeroradiographic process, among which are speed reduction in equipment, efficient use of ancillary personnel, reduced cost of materials, as well as no need for darkroom facility. ${ }^{24}$ Xeroradiograph is the most cost effective compared to either automatic processing or manual processing. 5,6

\section{Reduced exposure to radiation hazards}

Because there is no need to make multiple exposures as tissues of different densities and thicknesses can be recorded in one exposure, patient is at a very low risk of radiation hazards. ${ }^{21}$ However, some authors reported that radiation using xeroradiograph was $90 \%$ more than that for conventional radiograph. ${ }^{8}$ This contrasts with previous reports that exposure using xeroradiograph was a third to a half of that for conventional radiograph, ${ }^{7}$ but is in agreement with the report of Wilson and Grant. ${ }^{25}$ However, this should not cause any anxiety as it is shown that by increasing the kilo-voltage to at least 120 the exposure could be reduced by $60 \% .^{5}$

\section{Wide applications}

Generally, xeroradiography has interesting applications in the management of neoplasm of laryngopharyngeal area, mammary and joint region, as well as an aid in cephalometric analysis.

\section{POSSIBLE DISADVANTAGES OF XERORADIOGRAPHY}

One of the key characteristics of xeroradiography is the use of electrostatic charges in xeroradiographic process. Such charges stand the risk of being lost in confined humid oral environment in intraoral xeroradiograph. 5,22,26 This is very difficult to overcome.

Technical difficulties

Both the amount of radiation exposure and the thickness of xeroradiographic plate are linearly proportional. An increased thickness of the plate will increase the speed, because of the greater likelihood that the $x$-rays passing through the photoconducting layer will interact. ${ }^{27}$

\section{Fragile selenium coat}

The amorphous selenium photoconductor is a highly electrically stable layer. However, the layer is quite easily scratched. Notwithstanding, it has been observed that the surface shows good resistance to scratching, chipping and abrasion. As a result, placement and retention in confined area like the mouth would possibly be difficult., 19,22

\section{Transient Image Retention}

Rawls and 0 wen ${ }^{19}$ reported that xeroradiographic process involves residual charge patterns and therefore, the imaging process should be completed as soon as possible. However, as long as the charge pattern is retained, the technique allows multiple copies to be obtained from the pattern. 22,23

\section{Slower speed}

Comparatively, xeroradiography has a lower speed than halide radiographs. This can be significant when dealing with intraoral films. 21,26

\section{Technical limitations}

Certain technical limitations, such as low density of the selenium plate which requires increased doses of the $x$-rays administered make the technique not to be considered as a total substitute for halide radiograph. ${ }^{28}$

\section{POTENTIAL ENDODONTIC APPLICATIONS}

Xeroradiography has several effects on the soft tissues that make the technique potentially useful in endodontics. ${ }^{29}$ First, soft tissues on xeroradiographic films have well defined outlines that may permit confident evaluation of the soft tissue height and contour. Second, xeroradiographs provide greater overall soft tissue detail making possible evaluation of its density, texture, and contents. Third, the technique reveals soft tissues calcifications which are not easily discerned in conventional radiographs. ${ }^{6}$ This property may be employed in endodontics to visualized early pulpal calcifications. Other workers are of the view that some unique properties such as greater latitude of exposure, high resolving power, and the property of edge enhancement may be useful in endodontics. These properties may be exploited when detailed visualization of lamina dura, bony trabec- 
ulae, fine metal instruments like files, broaches etc, root apices, periodontal ligament spaces are required. ${ }^{7.8}$

Furthermore, bearing the foregoing xeroradiographic properties in mind, the technique may be employed to detect initial periapical changes, detect multiple roots, evaluate initial periapical healing after root canal therapy, and visualize early periodontal-endodontic lesions.

\section{CONCLUSIONS}

Dental xeroradiography has peculiar positive properties which enable both detailed bony and soft tissue examination, as well as subtle visualization of structures. These properties may be useful in endodontics. A revisit of this imaging system to explore its full endodontic potential is needed.

\section{REFERENCES}

1. Jafarzadeh $H$, Rosenberg PA. Pulse oximetry: review of a potential aid in endodontic diagnosis. J Endod 2009;35:329333.

2. Jafarzadeh $\mathrm{H}$, Udoye $\mathrm{Cl}$, Kinoshita Jl. The application of tooth temperature measurement in endodontic diagnosis: A review. J Endod 2008;34:1435-1440.

3. Jafarzadeh H. Laser Doppler flowmetry in endodontics: a review. Int Endod J 2009;42:476-490.

4. Gratt BM, Sickles EA, Parks CP. Xeroradiography of dental structures. I. Preliminary investigations. Oral Surg Oral Med Oral Pathol 1977;44:148-152.

5. Wolfe JN. Xerography of the breast. Geriatrics 1968;23:117121.

6. Gratt BM, Sickles EA, Silverman S Jr. Dental xeroradiography as an adjunct in the evaluation of oral cancer: a preliminary report. Oral Surg Oral Med Oral Pathol 1980;49:303308.

7. Gratt BM, Sickles EA, Nguyen NT. Dental xeroradiography for endodontics: a rapid X-ray system that produces highquality images. J Endod 1979;5:266-270.

8. Barkhordar RA, Nicholson RJ, Nguyen NT, Abbasi J. An evaluation of xeroradiographs and radiographs in length determination in endodontics. Oral Surg Oral Med Oral Pathol 1987;64:747-750.

9. Curry TS, Dowley JE, Murry RC. Christensen's Physics of the Diagnostic Radiology. Lea \& Febiger, Philadelphia 1990.

10. Doust BD, Ting YM. Xeroradiography of the larynx. Radiology 1974;110:727-730

11. Binnie WH, Stacey AJ, Davis R, Cawson R. Applications of xeroradiography in dentistry. J Dent 1975;3:99-104.
12. Grant BM, Sickles EA, Parks CR. Use of intraoral cassettes for dental xeroradiography. Oral Surg Oral Med Oral Pathol 1978;46:717-720.

13. White SC, Stafford ML, Beeninga LR. Intraoral xeroradiography. Oral Surg Oral Med Oral Pathol 1978;46:862-870.

14. Xerox Corporation. Xeroradiography for temporomandibular Joint. Med Appl Bullet 1973;115.

15. Kalisher L, Olson DJ, Guralnick WC. The application of xeroradiography in diagnosis of maxillofacial problems. J Can Assoc Radiol 1976;27:52-56.

16. Pogorzelska-Stronczak B. Attempted application of xeroradiography in stomatology. Pol Przegl Radiol Med Nukl 1963;27:265-275.

17. Ferguson MM, Davison M, Evans A, Mason WN. Application of xeroradiography in sialography. Int J Oral Surg 1976;5:176-179.

18. Jeromin LS, Geddes GF, White SC, Gratt BM. Xeroradiography for intraoral dental radiology. A process description. Oral Surg Oral Med Oral Pathol 1980;49:178-183.

19. Rawls HR, Owen WD. The dental prognosis for xeroradiography. Oral Surg Oral Med Oral Pathol 1972;33:476-480.

20. Roach JF, Hilleboe HE. Xeroradiography. Am J Roentgenol Radium Ther Nucl Med 1955;73:5-9.

21. Wolfe JN. Xeroradiography of the bones, joints, and soft tissues. Radiology 1969;93:583-587.

22. Mc Master RC. New developments in xeroradiography. Nondestructive Testing 1951;10:8-25.

23. Gould HR, Ruzicka FF Jr, Sanchez-Ubeda R, Perez J. Xeroradiography of the breast. Am J Roentgenol Radium Ther Nucl Med 1960;84:220-223.

24. Lapinskas VA, Lapinskene AV. Electroroentgenography (xeroradiography) and prospects of its use in dentistry. Stomatologiia (Mosk) 1968;47:35-38.

25. Wilson NH, Grant AA. A clinical trial of dental xeroradiography. Br Dent J 1986 8;161:327-335.

26. Vyverberg RG, Clark HE, Dessauer JH. Industrial xeroradiography in 1955. Nondestructive Testing 1955;13:35-40.

27. Donovan JL. Xeroradiographic properties of amorphous selenium. J Appl Phys 1970;41:2109.

28. Lopez J Jr. Xeroradiography in dentistry. J Am Dent Assoc 1976;92:106-110.

29. Zocchi M. Xeroradiography. Technic, methodology, and image characteristics. Rev Stomatol Chir Maxillofac 1982;83:103-106.

30. White SC, Gratt BM. Clinical trials of intraoral dental xeroradiography. J Am Dent Assoc 1979;99:810-816. 